\title{
Hemoglobin Levels Above Anemia Thresholds Are Maximally Predictive for Long-Term Survival in COPD With Chronic Respiratory Failure
}

\author{
Florian Kollert MD, Andrea Tippelt, Carolin Müller, Rudolf A Jörres PhD, \\ Christine Porzelius, Michael Pfeifer MD, and Stephan Budweiser MD
}

\begin{abstract}
BACKGROUND: In patients with COPD, chronic anemia is known as an unfavorable prognostic factor. Whether the association between hemoglobin $(\mathrm{Hb})$ levels and long-term survival is restricted to anemia or extends to higher Hb levels has not yet been systematically assessed. METHODS: We determined $\mathrm{Hb}$ levels in 309 subjects with COPD and chronic respiratory failure prior to initiation of noninvasive ventilation, accounting for confounders that might affect $\mathrm{Hb}$. Subjects were categorized as anemic $(\mathrm{Hb}<12 \mathrm{~g} / \mathrm{dL}$ in females, $\mathrm{Hb}<13 \mathrm{~g} / \mathrm{dL}$ in males $)$, polycythemic $(\mathrm{Hb} \geq 15 \mathrm{~g} / \mathrm{dL}$ in females, $\mathrm{Hb} \geq 17 \mathrm{~g} / \mathrm{dL}$ in males), or normocythemic. In addition, percentiles of $\mathrm{Hb}$ values were analyzed with regard to mortality from any cause. RESULTS: Two-hundred seven subjects $(67.0 \%)$ showed normal Hb levels, 46 (14.9\%) had anemia, and $56(18.1 \%)$ had polycythemia. Polycythemic subjects showed a higher survival rate than anemic $(P=.01)$ and normocythemic subjects $(P=.043)$. In a univariate Cox hazards model, $\mathrm{Hb}$ was associated with long-term survival (hazard ratio 0.855 ; 95\% CI 0.783-0.934, $P<.001)$. The 58th percentiles of $\mathrm{Hb}(14.3 \mathrm{~g} / \mathrm{dL}$ in females, $15.1 \mathrm{~g} / \mathrm{dL}$ in males $)$ yielded the highest discriminative value for predicting survival (hazard ratio $0.463,95 \%$ CI 0.324 $0.660, P<.001)$. In the multivariate analysis this cutoff was an independent predictor for survival (hazard ratio $0.627,95 \% \mathrm{CI} 0.414-0.949, P=.03$ ), in addition to age and body mass index. CONCLUSIONS: In subjects with COPD and chronic respiratory failure undergoing treatment with noninvasive ventilation and LTOT, high $\mathrm{Hb}$ levels are associated with better long-term survival. The optimal cutoff level for prediction was above the established threshold defining anemia. Thus, predicting survival only on the basis of anemia does not fully utilize the prognostic potential of $\mathbf{H b}$ values in COPD. Key words: COPD; chronic respiratory failure; long-term survival; hemoglobin; anemia; noninvasive ventilation; polycythemia. [Respir Care 2013;58(7):1204-1212. (c) 2013 Daedalus Enterprises]
\end{abstract}

\section{Introduction}

COPD is characterized by chronic air-flow limitation, inflammation, and lung remodeling, ${ }^{1}$ and associated with

The authors are affiliated with the Center for Pneumology, Donaustauf Hospital, Donaustauf, Germany, with the exception of Dr Jörres, who is affiliated with the Institute and Out-Patient Clinic for Occupational, Social, and Environmental Medicine, Ludwig Maximilians University, Munich, Germany, and Mrs Porzelius, who is affiliated with the Institute of Medical Biometry and Medical Informatics, University Medical Center Freiburg, Freiburg, Germany. Dr Kollert is also affiliated with the Department of Rheumatology and Clinical Immunology, University Medical Center, Freiburg, Germany. Drs Kollert and Pfeifer are also affiliated with the Department of Internal Medicine II, Division of Respirology, University of extra-pulmonary systemic manifestations (eg, cardiovascular diseases, malnutrition, osteoporosis, renal failure, depression, and anxiety). ${ }^{2-4}$ Anemia, most likely of multifacRegensburg, Regensburg, Germany. Dr Budweiser is also affiliated with the
Department of Internal Medicine III, Division of Pulmonary and Respiratory
Medicine, RoMed Clinical Center, Rosenheim, Germany.

The authors have disclosed no conflicts of interest.

Correspondence: Stephan Budweiser MD, Division of Pulmonary and Respiratory Medicine, Department of Internal Medicine III, RoMed Clinical Center Rosenheim, Pettenkoferstraße 10, 83022 Rosenheim, Germany. E-mail: stephan.budweiser@ro-med.de.

DOI: $10.4187 /$ respcare.01961 
torial origin, is also a common comorbidity. ${ }^{5-8}$ In a large cohort of subjects with severe COPD receiving long-term oxygen therapy (LTOT), Chambellan and co-workers found that a low hematocrit $(\mathrm{Hc})$ was not uncommon, and was associated with higher mortality and morbidity. ${ }^{7}$ Also, in stable COPD of widely ranging disease severity the prevalence of anemia was high (17\%) and related to a reduction of functional capacity and survival time. ${ }^{8}$ Recent data showed anemia in $18 \%$ of COPD patients treated for acute respiratory failure, and a link between anemia and 90-day mortality. ${ }^{9}$

However, hypoxia-induced "secondary" polycythemia is also common in severe COPD. In contrast to anemia, polycythemia may reflect that an adequate compensatory physiologic response to hypoxemia is still present, despite the systemic inflammation. Historically, phlebotomy has been used in patients with high hemoglobin $(\mathrm{Hb}) / \mathrm{Hc}$ levels. Moreover, in numerous studies, functional benefits of phlebotomy in hypoxic pulmonary disease have been described.10-16 Conversely, polycythemia contributes to the development of cor pulmonale and pulmonary hypertension, which are linked to poor prognosis. ${ }^{17}$ However, most of these studies were performed prior to the widespread use of LTOT and domiciliary noninvasive ventilation (NIV), and large systematic trials on phlebotomy in polycythemic patients are lacking. For patients with polycythemia due to hypoxic lung diseases, guidelines primarily recommend the evaluation for LTOT or mechanical ventilation by a respiratory physician. ${ }^{18}$ Phlebotomy is suggested only in patients with symptoms of hyperviscosity or Hc above $56 \% .{ }^{18}$

In the study by Cote et al, the prevalence of polycythemia $(\mathrm{Hb} \geq 17 \mathrm{~g} / \mathrm{dL})$ was low $(5.9 \%)$, and not associated with worsened outcomes in COPD patients. ${ }^{8}$ Chambellan et al found the longest survival in polycythemic patients receiving LTOT. However, their analysis was based on $\mathrm{Hc}$ levels and did not exclude patients with comorbidities or conditions that might interfere with red blood cell count. Accordingly, it was claimed that more studies would be desirable to explore the impact of red cell mass on clinical outcomes, in particular, survival. ${ }^{7,8}$

Based on these considerations, we investigated the prognostic impact of $\mathrm{Hb}$ levels in a large cohort of COPD subjects with chronic respiratory failure, who were under optimized therapy, including LTOT and domiciliary NIV, while accounting for major confounders of $\mathrm{Hb}$ levels. The aim was to assess whether the association of $\mathrm{Hb}$ and mortality is linear or not, and whether the optimal $\mathrm{Hb}$ cutoff levels for the prediction of long-term survival are similar to or different from the common clinically used cutoff values of anemia or polycythemia.

\section{QUICK LOOK}

\section{Current knowledge}

In patients with COPD, anemia is a common comorbidity and is associated with reduced functional capacity, poor outcome, and early mortality. Anemia may represent inability to compensate for hypoxemia in COPD patients with chronic respiratory failure.

\section{What this paper contributes to our knowledge}

In patients with COPD and chronic respiratory failure, higher hemoglobin level was associated with longer survival. Hemoglobin of $\geq 14.3 \mathrm{~g} / \mathrm{dL}$ in females, and $\geq 15.1 \mathrm{~g} / \mathrm{dL}$ in males was independently associated with better outcome.

\section{Methods}

\section{Study Subjects}

Patients were identified from an electronic database of the Donaustauf Hospital Center for Pneumology, in which all patients treated with domiciliary NIV are registered. The decision for NIV was made on the basis of international recommendations, ${ }^{19}$ pronounced nocturnal hypercapnia, or clinical criteria. Demographic and anthropometric data, as well as diagnoses; concomitant diseases (coronary heart disease, left heart failure, arterial hypertension, diabetes mellitus, cardiac arrhythmia); medication (angiotensin-converting-enzyme inhibitors, angiotensinreceptor blockers, $\beta$ blockers, $\beta_{2}$ agonists, parasympatholytics, theophylline, systemic steroids); blood gas values; parameters of lung function and exercise testing; and laboratory parameters were documented. Starting in January 2002, data were entered prospectively. In the present analysis, only patients with COPD stage III/IV (GOLD, Global Initiative for Chronic Obstructive Lung Disease) who received NIV between April 1992 and March 2007 were included. The diagnosis was based on clinical history and a ratio of $\mathrm{FEV}_{1}$ to inspiratory vital capacity of $<70 \%$, and $\mathrm{FEV}_{1}$ being $<30 \%$ of predicted or $<50 \%$ of predicted plus chronic respiratory failure. ${ }^{1}$

We included only patients in whom blood count data were obtained at admission prior to the initiation of NIV. Moreover, based on the medical records, patients with the following confounders of $\mathrm{Hb}$ levels not causatively related to COPD were excluded: previous invasive ventilation; renal failure with estimated glomerular filtration rate $<30 \mathrm{~mL} / \mathrm{min} / 1.73 \mathrm{~m}^{2}$; malignancies/hematological disorders within the last 5 years; surgeries, interventions, accidents or hemorrhage within the last 3 months; additional 
chronic inflammatory, autoimmune or infectious disease; previous gastrointestinal resection; substitution of iron, folate, or vitamin $\mathrm{B}_{12}$; and phlebotomy due to polycythemia or blood transfusion.

\section{Measurements}

Demographic, anthropometric, and laboratory data $(\mathrm{Hb}$, leukocytes, C-reactive protein, creatinine) were assessed upon admission. Subjects were categorized as anemic $(\mathrm{Hb}<12 \mathrm{~g} / \mathrm{dL}$ in females, $\mathrm{Hb}<13 \mathrm{~g} / \mathrm{dL}$ in males $),{ }^{20}$ polycythemic $(\mathrm{Hb} 15 \geq \mathrm{g} / \mathrm{dL}$ in females, $\mathrm{Hb} \geq 17 \mathrm{~g} / \mathrm{dL}$ in males), ${ }^{8}$ or normocythemic. The estimated glomerular filtration rate was calculated by the Modification of Diet in Renal Diseases (MDRD) equation, which is known to be particularly accurate in elderly patients. ${ }^{21}$

Spirometry and body plethysmography (MasterScreen, Cardinal Health, Höchberg, Germany) were performed according to the guidelines of the American Thoracic Society/European Respiratory Society,22 using European Respiratory Society reference values. ${ }^{23}$ Six-min walk distance was determined according to the American Thoracic Society statement, ${ }^{24}$ using reference values by Enright and Sherrill. ${ }^{25}$ Blood gases were assessed from the hyperemic earlobe after incision, using a capillary tube and blood gas analyzer (RapidLab, Bayer, Leverkusen, Germany). Only values obtained without oxygen supply were included.

\section{Follow-up}

Vital status was determined through telephone contact to the subjects' relatives or family physicians, and by review of medical records. Informed written consent of the subjects or their relatives was obtained. All subjects underwent a follow-up period of at least 5 months, until July 1, 2007, or death. Mortality was documented as overall mortality, including all causes of death. The study approach was approved by the local ethics committee of the University of Regensburg.

\section{Statistical Analysis}

Normality of data distribution was checked by the Kolmogorov-Smirnov test. Data are shown as medians and IQRs. For the comparison of subgroups the non-parametric Kruskal-Wallis test was used, for categorical variables the chi-square test. Univariate Cox proportional hazards regression models were run to assess the impact of single predictors on survival. Predictors with $P<.05$ were included in a multivariate Cox proportional hazards regression model to adjust for prognostic factors other than $\mathrm{Hb}$.

To identify the optimal cutoff values for $\mathrm{Hb}$ and to compare them with the standard cutoff values, the following analyses were conducted. For each individual, the prob- ability of death within 1 year was obtained from the multivariate Cox proportional hazards model, as described above. The relationship between $\mathrm{Hb}$ level and these probabilities was visualized in a scatter plot, together with a non-linear LOESS (locally weighted polynomial regression) smoother. Each percentile of $\mathrm{Hb}$, taken separately for females and males, was used to define 2 subgroups with low and high $\mathrm{Hb}$ level. Univariate Cox proportional hazards models were fitted for each of these levels, and the one with the smallest $P$ value yielded the optimal cutoff for $\mathrm{Hb}$. Survival probabilities of the commonly used $\mathrm{Hb}$ categories and the ones identified by us were plotted as Kaplan-Meier curves, which were compared by the log rank test. To compare the prognostic impact of the newly found $\mathrm{Hb}$ cutoff values and the standard $\mathrm{Hb}$ categories, univariate Cox proportional hazards regression models were employed.

\section{Results}

\section{Subjects' Characteristics}

A total of 534 subjects with COPD GOLD stage III/IV were analyzed. After exclusion of subjects with comorbidities, or conditions potentially contributing to abnormalities in red blood cell count, and subjects with a lack of follow-up, 309 subjects remained. Their median (IQR) $\mathrm{Hb}$ was $14.5 \mathrm{~g} / \mathrm{dL}(15.9-13.1 \mathrm{~g} / \mathrm{dL})$, and 207 subjects $(67.0 \%)$ were categorized as normocythemic, $102(33.0 \%)$ as abnormal. Among the latter, 46 subjects $(14.9 \%)$ were anemic and $56(18.1 \%)$ polycythemic. There were differences in the distributions of sex $(P=.002)$, age $(P<.001)$, survival time $(P=.008)$, and comorbidities between anemic, normocythemic and polycythemic subjects (Table 1). Medical therapy (angiotensin-converting-enzyme inhibitors, angiotensin-receptor blockers, $\beta$ blockers, $\beta_{2}$ agonists, parasympatholytics, theophylline, systemic steroids) was not linked to the presence of anemia.

In males $(n=222), \mathrm{Hb}$ abnormalities were predominately due to anemia $(n=40,18.0 \%)$ and not polycythemia $(n=31,14.0 \%)$. Females $(n=87)$ mostly showed polycythemia $(n=56,28.7 \%)$, while anemia occurred less frequently $(n=6,6.9 \%, P=.002)$. Before inclusion, 170 subjects $(55.0 \%)$ were treated with LTOT. At discharge, all subjects were treated with NIV $(n=309,100 \%)$ and nearly all had LTOT $(n=293,94.8 \%)$. Further subject characteristics are given in Table 1.

\section{Hemoglobin Levels and Long-Term Survival}

A total of 139 subjects $(45.0 \%)$ died during the study period (mean $\pm \mathrm{SD}$ follow-up $36.1 \pm 31.1$ months). The causes of death were cardiopulmonary 116 (83.5\%), malignancy 7 (5.0\%), other $5(3.6 \%)$, and unknown 11 (7.9\%). 
Table 1. Subjects' Demographic and Clinical Characteristics According to Hemoglobin Categories

\begin{tabular}{|c|c|c|c|c|}
\hline & Anemia* & Normocythemia & Polycythemia & $P$ \\
\hline Subjects, no. (\%) & $46(14.9)$ & $207(67.0)$ & $56(18.1\}$ & \\
\hline Female/male, no. & $6 / 40$ & $56 / 151$ & $25 / 31$ & $.002 \dagger$ \\
\hline Age, y & $70.3(73.8-62.8)$ & $66.2(71.4-59.1)$ & $61.2(68.4-55.4)$ & $<.001$ \\
\hline Body mass index, $\mathrm{kg} / \mathrm{m}^{2} \ddagger$ & $24.3(30.0-20.6)$ & $27.7(33.0-21.6)$ & $29.5(34.8-22.6)$ & .09 \\
\hline Long-term oxygen therapy, no. (\%) & $45(97.8)$ & $196(94.7)$ & $52(92.9)$ & $.52 \dagger$ \\
\hline Percent-of-predicted $\mathrm{FEV}_{1} \neq$ & $28.5(38.0-22.4)$ & $29.8(38.0-22.3)$ & $31.5(38.0-25.0)$ & .37 \\
\hline $\mathrm{P}_{\mathrm{aO}_{2}}, \mathrm{~mm} \mathrm{Hg}$ & $54.5(63.3-46.0)$ & $49.5-(55.0-42.8)$ & $46.0(50.0-40.5)$ & .002 \\
\hline $\mathrm{P}_{\mathrm{aCO}_{2}}, \mathrm{~mm} \mathrm{Hg} \ddagger$ & $48.5(56.5-40.8)$ & $52.0(58.0-48.0)$ & $56.0(61.5-50.5)$ & .62 \\
\hline $\mathrm{pH}+$ & $7.45(7.49-7.4)$ & $7.42(7.45-7.39)$ & $7.4(7.43-7.37)$ & .003 \\
\hline 6-min walk distance, $\mathrm{m} \ddagger$ & $267(360-180)$ & $264(340-174)$ & $336(371-235)$ & .08 \\
\hline Leukocytes, $10^{3} / \mu \mathrm{L}$ & $9.3(11.7-7.6)$ & $9.2(11.7-7.5)$ & $9.4(12.3-7.4)$ & .89 \\
\hline C-reactive protein, $\mathrm{mg} / \mathrm{L} \ddagger$ & $8.7(34.8-4.0)$ & $6.7(21.7-4.5)$ & $8.6(20.0-4.8)$ & .90 \\
\hline Creatinine, mmol/L & $70.7(97.3-61.9)$ & $79.6(97.3-61.9)$ & $70.7(88.4-61.9)$ & .29 \\
\hline $\begin{array}{l}\text { Estimated glomerular filtration rate, } \\
\mathrm{mL} / \mathrm{min} / 1.73 \mathrm{~m}^{2} \ddagger\end{array}$ & $89.3(117.2-63.7)$ & $86.8(103.1-68.8)$ & $89.4(99.6-75.3)$ & .94 \\
\hline Coronary heart disease, no. (\%) & $14(30.4)$ & $29(14.0)$ & $4(7.1)$ & .003 \\
\hline Left heart failure, no. (\%) & $6(13.0)$ & $40(19.3)$ & $9(16.1)$ & .56 \\
\hline Arterial hypertension, no. (\%) & $21(45.7)$ & $84(40.6)$ & $23(41.1)$ & .82 \\
\hline Diabetes mellitus, no. (\%) & $20(43.5)$ & $43(20.8)$ & $13(23.2)$ & .005 \\
\hline Cardiac arrhythmia, no. (\%) & $13(28.3)$ & $29(14.0)$ & $2(3.6)$ & .002 \\
\hline Median survival time, months & 29 & 51 & 112 & $.008 \S$ \\
\hline \multicolumn{5}{|c|}{ 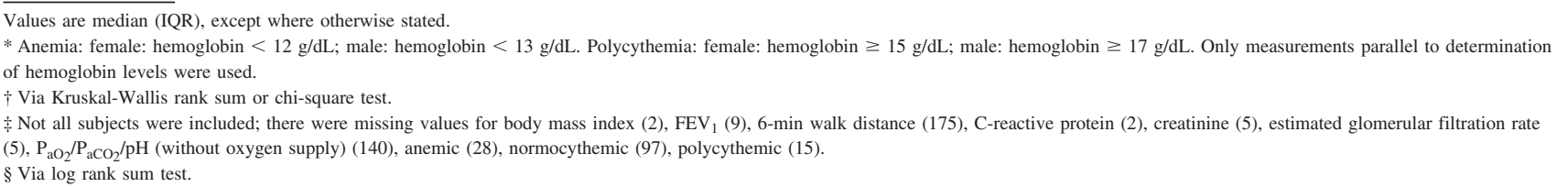 } \\
\hline
\end{tabular}

Twenty-two anemic (15.8\%), 95 normocythemic $(68.3 \%)$, and 22 polycythemic (15.8\%) subjects died. The median survival of polycythemic subjects was 112 months, while normocythemic subjects survived 51 and anemic subjects 29 months. The survival probability of polycythemic subjects was higher than that of normocythemic $(P=.043)$ and anemic subjects $(P=.01)$, and that of normocythemic was higher than that of anemic subjects $(P=.041$, Fig. 1). The 1-year survival probability of all subjects as a function of $\mathrm{Hb}$ values is depicted in Figure 2.

When analyzing every percentile of $\mathrm{Hb}$ values with regard to long-term survival, the optimal cutoff value of $\mathrm{Hb}$ was identified as $14.3 \mathrm{~g} / \mathrm{dL}$ for females and $15.1 \mathrm{~g} / \mathrm{dL}$ for males (58th percentiles each, Table 2). Regarding the association with the probability of death, these values were superior to the cutoffs used for the definition of anemia according to the World Health Organization $(\mathrm{Hb}<12 \mathrm{~g} / \mathrm{dL}$ in females, $\mathrm{Hb}<13 \mathrm{~g} / \mathrm{dL}$ in males, Fig. 3).

\section{Multivariate Analysis}

In the univariate Cox proportional hazards models, age, sex, body mass index (BMI), $\mathrm{FEV}_{1}, 6$-min walk distance,

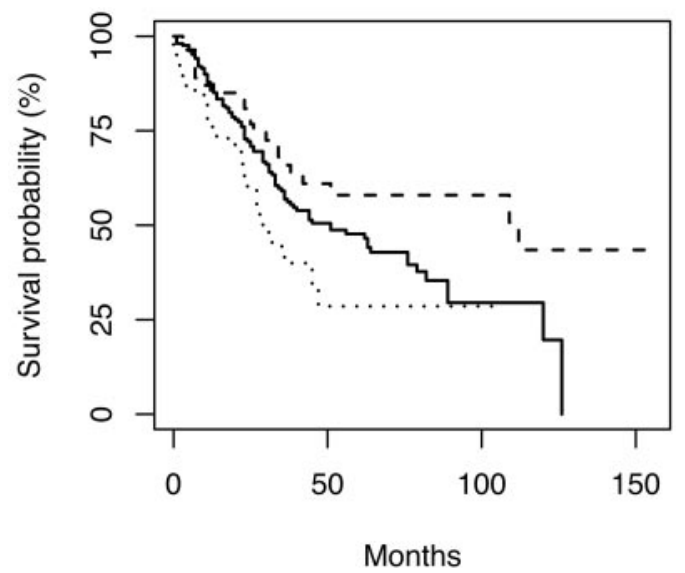

Fig. 1. Kaplan-Meier survival curves for anemic (dotted line), normocythemic (solid line), and polycythemic (dashed line) subjects. The log rank sum test showed differences between these conditions: $P=.043$ for polycythemic vs normocythemic, $P=.01$ for polycythemic vs anemic, $P=.041$ for normocythemic vs anemic.

$\mathrm{Hb}$, leukocyte levels, and arterial hypertension were associated with survival $(P<.05$ for each, Table 3$)$. A multivariate Cox proportional hazards model containing age, sex, BMI, $\mathrm{FEV}_{1}, \mathrm{Hb}$, leukocyte level, and arterial hyper- 


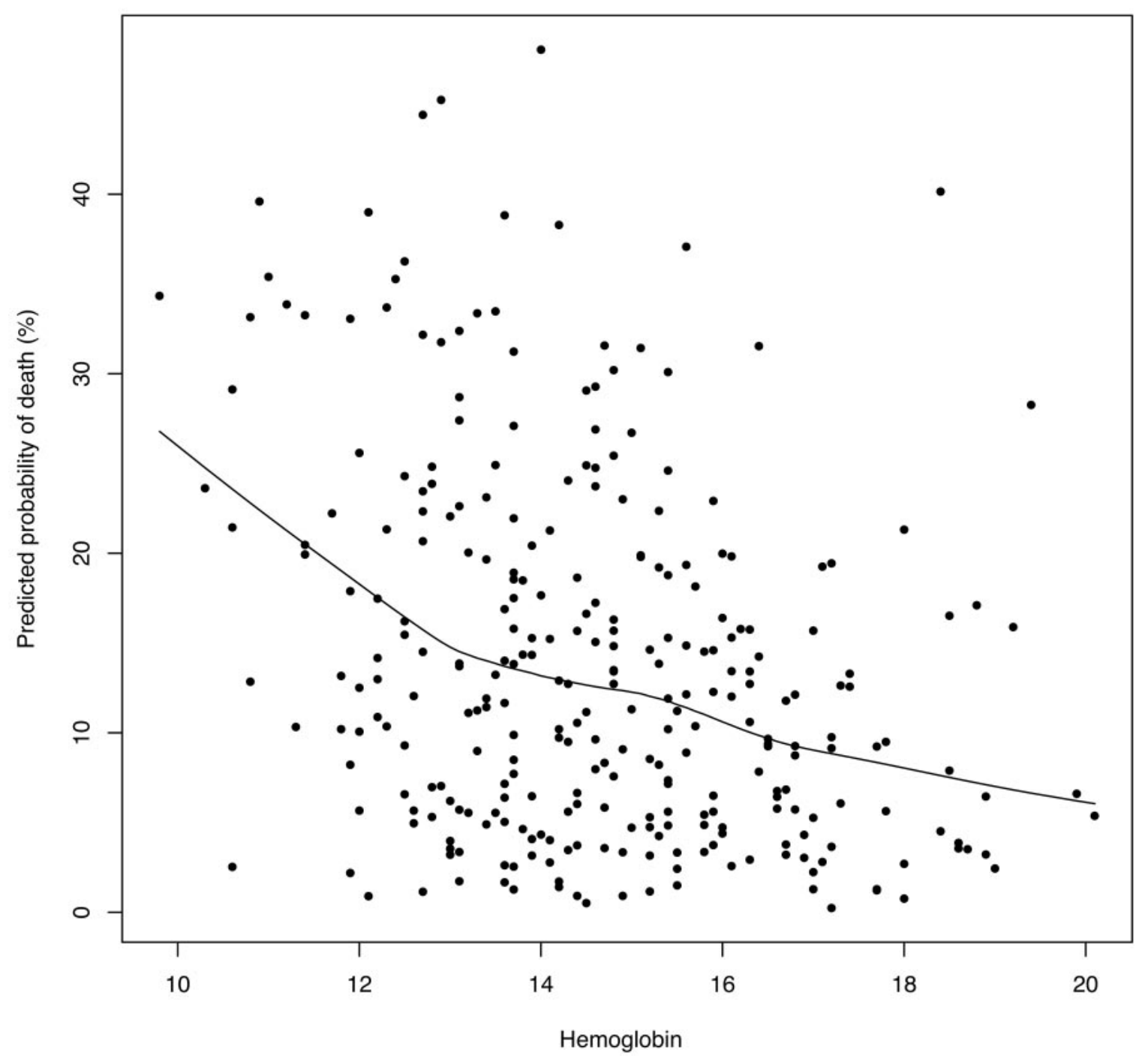

Fig. 2. LOESS (locally weighted polynomial regression) smoother curve for hemoglobin level versus predicted probability of death (1 year).

Table 2. Univariate Cox Proportional Hazards Models for the Prediction of Death Regarding Percentiles of Hemoglobin

\begin{tabular}{|c|c|c|c|c|}
\hline \multirow{2}{*}{ Percentile } & \multicolumn{2}{|c|}{ Hemoglobin Value } & \multirow{2}{*}{$\begin{array}{l}\text { Hazard Ratio } \\
\qquad(95 \% \mathrm{CI})\end{array}$} & \multirow{2}{*}{$P$} \\
\hline & Female & Male & & \\
\hline 10th & 12.16 & 12.20 & $0.568(0.325-0.992)$ & .047 \\
\hline 20th & 12.80 & 13.02 & $0.682(0.440-1.057)$ & .09 \\
\hline 30th & 13.10 & 13.70 & $0.585(0.404-0.846)$ & .004 \\
\hline 40th & 13.54 & 14.20 & $0.635(0.450-0.895)$ & .009 \\
\hline 50 th & 13.90 & 14.60 & $0.549(0.391-0.770)$ & .001 \\
\hline 58th & 14.30 & 15.10 & $0.463(0.324-0.660)$ & $<.001$ \\
\hline 60th & 14.40 & 15.26 & $0.490(0.343-0.701)$ & $<.001$ \\
\hline 70th & 14.90 & 15.80 & $0.514(0.350-0.755)$ & .001 \\
\hline 80th & 15.74 & 16.40 & $0.653(0.430-0.990)$ & .045 \\
\hline 90th & 16.94 & 17.67 & $0.540(0.303-0.961)$ & .04 \\
\hline
\end{tabular}

tension revealed only age and BMI to be predictive, while $\mathrm{Hb}$ as a continuous linear variable failed statistical significance $(P=.09)$. However, when the categorical Hb cutoff values (female $14.3 \mathrm{~g} / \mathrm{dL}$, male $15.1 \mathrm{~g} / \mathrm{dL}$ ) were included in the multivariate panel, these cutoffs were also revealed as independent predictors of survival (Table 4), which indicates a nonlinear relationship.

\section{Discussion}

The present study demonstrates that in subjects with severe COPD and chronic respiratory failure, $\mathrm{Hb}$ levels prior to the initiation of NIV were linked to long-term survival. We identified $\mathrm{Hb}$ values of $14.3 \mathrm{~g} / \mathrm{dL}$ for females and $15.1 \mathrm{~g} / \mathrm{dL}$ for males as conferring the highest predictive value. These $\mathrm{Hb}$ values were, in addition to age and 


\section{Hemoglobin Levels Above Anemia Thresholds}

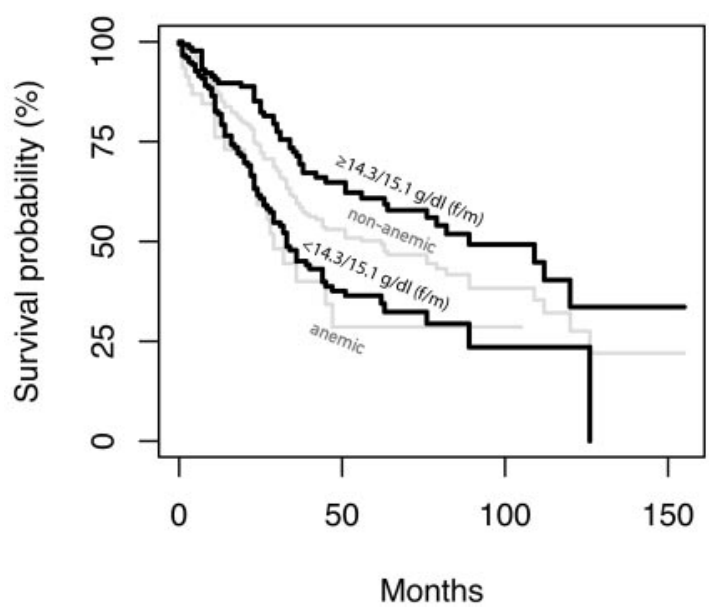

Fig. 3. Kaplan-Meier survival curves of subjects either above or below the optimal cutoff value. The upper black line illustrates either female subjects with hemoglobin $\geq 14.3 \mathrm{~g} / \mathrm{dL}$ or male subjects with hemoglobin $\geq 15.1 \mathrm{~g} / \mathrm{dL}$. The lower black line illustrates either female subjects with hemoglobin $<14.3 \mathrm{~g} / \mathrm{dL}$ or male subjects with hemoglobin $<15.1 \mathrm{~g} / \mathrm{dL}$. The grey lines show survival of subjects with or without anemia using the threshold of the World Health Organization ( $12 \mathrm{~g} / \mathrm{dL}$ for female or $13 \mathrm{~g} / \mathrm{dL}$ for male). The black lines represent the 58th percentile: females $14.3 \mathrm{~g} / \mathrm{dL}$, males $15.1 \mathrm{~g} / \mathrm{dL}$, hazard ratio 0.463 , IQR $0.324-0.660, P<.001$. The gray lines represents anemic versus non-anemic subjects: hazard ratio 0.572 , IQR $0.361-0.907, P=.02$.

Table 3. Univariate Cox Proportional Hazards Models for Predicted Probability of Death

\begin{tabular}{lcc}
\hline \hline \multicolumn{1}{c}{ Variable } & $\begin{array}{c}\text { Hazard Ratio } \\
(95 \% \mathrm{CI})\end{array}$ & $P$ \\
\hline Age & $1.064(1.041-1.088)$ & $<.001$ \\
Female/male & $1.503(1.003-2.252)$ & .049 \\
$\mathrm{BMI}^{*}$ & $0.912(0.889-0.936)$ & $<.001$ \\
$\mathrm{FEV}_{1}{ }^{*}$ & $0.970(0.950-0.989)$ & .002 \\
$\mathrm{P}_{\mathrm{aO}_{2}}$ (without oxygen supply)* & $0.969(0.969-1.024)$ & .79 \\
$\mathrm{P}_{\mathrm{aCO}_{2}}$ (without oxygen supply)* & $1.003(0.974-1.034)$ & .84 \\
6-min walk distance* & $0.996(0.993-0.999)$ & .02 \\
$\mathrm{Hemoglobin}^{*}$ & $0.855(0.783-0.934)$ & $<.001$ \\
Leukocytes & $1.067(1.025-1.111)$ & .002 \\
C-reactive protein* $^{*}$ & $1.002(0.999-1.005)$ & .28 \\
Creatinine* & $1.441(0.781-2.662)$ & .24 \\
Estimated glomerular filtration rate* & $0.999(0.993-1.004)$ & .65 \\
Coronary heart disease & $1.227(0.746-2.016)$ & .42 \\
Left heart failure & $1.296(0.873-1.924)$ & .20 \\
Arterial hypertension & $0.609(0.426-0.870)$ & .007 \\
Diabetes mellitus & $0.988(0.659-1.482)$ & .95 \\
Cardiac arrhythmia & $1.559(0.968-2.641)$ & .07 \\
& &
\end{tabular}

* Not all subjects were included; there were missing values for BMI (2), $\mathrm{FEV}_{1}$ (9), 6-min walk distance (175), C-reactive protein (2), creatinine (5), estimated glomerular filtration rate (5), $\mathrm{P}_{\mathrm{aO}_{2}} / \mathrm{P}_{\mathrm{aCO}} / \mathrm{pH}$ (140), anemia (28), normocythemia (97), and polycythemia (15).

BMI, independent predictors for survival, and markedly higher than the World Health Organization's definitions of
Table 4. Multivariate Cox Proportional Hazards Model for Predicted Probability of Death*

\begin{tabular}{lcc}
\hline \hline & $\begin{array}{c}\text { Hazard Ratio } \\
(95 \% \mathrm{CI})\end{array}$ & $P$ \\
\hline Age & $1.056(1.032-1.081)$ & $<.001$ \\
Body mass index & $0.915(0.890-0.941)$ & $<.001$ \\
Hemoglobin cut-off: & $0.627(0.414-0.949)$ & .03 \\
$\quad$ female $14.3 \mathrm{~g} / \mathrm{L}$, & & \\
male $15.1 \mathrm{~g} / \mathrm{L}$ & &
\end{tabular}

* 6-min walk distance was excluded due to a large number of missing values (175).

anemia. Our findings demonstrate that in subjects with COPD and chronic respiratory failure the prognostic value of $\mathrm{Hb}$ is not fully exploited when only using the common cutoff values for anemia that have been introduced to define pathological conditions, but not as clinical predictors.

As part of the view that COPD is a disease with multiple alterations beyond the lung, ${ }^{2}$ chronic anemia has been revealed as a common systemic manifestation. ${ }^{6-9}$ Low red cell mass impairs pulmonary hemodynamics, oxygen delivery, and gas exchange, ${ }^{6}$ which seems particularly relevant for COPD patients presenting with chronic respiratory failure. Conversely, polycythemia can contribute to pulmonary hypertension, reduced cerebral blood flow, and increased risk of venous thromboembolic disease, ${ }^{26,27}$ and thus may also negatively influence the prognosis. On the other hand, a higher red cell mass may indicate that an adequate physiologic response to hypoxemia is still present, which may be particularly relevant in a systemic inflammatory disease such as COPD. Irrespective of these considerations, it is an open question whether the World Health Organization's definition of anemia or other definitions adequately utilize the information conferred by $\mathrm{Hb}$ in COPD. Therefore, we analyzed the impact of a wide range of $\mathrm{Hb}$ levels on long-term survival in COPD patients undergoing NIV and LTOT in detail.

According to established definitions, $14.9 \%$ of the subjects of our sample presented with anemia, while $18.1 \%$ were polycythemic. In comparison to earlier studies ${ }^{7-9}$ the present cohort comprised a considerably higher proportion of subjects with polycythemia. These subjects also showed a higher survival than those with anemia and even normocythemia. Using similar definitions, a study on stable, only moderately ill, predominately male (96\%) COPD subjects also found anemia to be common $(17.1 \%)$ and associated with higher mortality, while polycythemia was less frequent $(5.9 \%)$. The prognostic value of polycythemia versus normoglobulia and anemia was not explicitly reported, but survival was at least not different between polycythemic and non-polycythemic subjects. ${ }^{8}$ In a large investigation of subjects with COPD and hypoxemic respiratory failure requiring $\mathrm{LTOT}^{7}$ anemia occurred in $8.2 \%$ of fe- 
males and $12.6 \%$ of males, while polycythemia again was present in only $5.9 \%$ of females and $8.9 \%$ of males, and associated with better survival. However, these findings were based on the assessment of $\mathrm{Hc}$ and not Hb. ${ }^{7}$ In contrast to $\mathrm{Hc}, \mathrm{Hb}$ is a direct measure for oxygen carrying capacity, more stable against changes in plasma volume, and thus more reliable for the assessment of anemia, while Hc may underestimate anemia. ${ }^{28}$ Moreover, in comparison to our investigation, the authors provided no data on comorbidities (eg, cancer, renal failure, or other chronic inflammatory diseases) or conditions (eg, gastrointestinal hemorrhage or blood loss) that might lead to changes in the red blood cell count. In our experience, this is a substantial proportion of patients, and a potential source of bias, as most of these comorbidities per se influence survival. We had to exclude $42 \%$ of primarily considered patients to circumvent this.

Nonetheless, the previously studied population ${ }^{7}$ appeared to be comparable to our cohort, insofar as all subjects received LTOT. The fact that the prevalence of polycythemia was lower than in our cohort was possibly due to a more severely impaired gas exchange in our study cohort, as indicated by chronic hypercapnia and the need for NIV. The beneficial effect of polycythemia on survival stands in contrast to the traditional view on COPD. ${ }^{14}$ As all the subjects in the present study received NIV and LTOT, which counteract polycythemia and hyperviscosity, ${ }^{29-31,18}$ the "protective" effect of polycythemia might, however, be true only for patients with optimized treatment.

Our results confirm the high prevalence of anemia $(14.9 \%)$ and its association with reduced survival in COPD, ${ }^{7-9}$ specifically in patients with chronic respiratory failure. Univariate Cox regression analyses showed $\mathrm{Hb}$ to be a predictor of long-term survival, similarly to age, sex, BMI, $\mathrm{FEV}_{1}$, 6-min walk distance, and leukocyte number. In a multivariate model, however, $\mathrm{Hb}$ as a continuous variable failed statistical significance $(P=.09)$. In view of the inevitable correlations between predictors, this does not appear as an unexpected finding. In the study by Chambellan et al, ${ }^{7}$ red blood cell mass in terms of $\mathrm{Hc}$ was found as an independent prognostic factor. However, the authors did not exclude patients with severe comorbidities that are often associated with both low $\mathrm{Hb}$ and worse long-term survival. ${ }^{7}$ This may have led to an overestimation of the prognostic impact of red cell mass in their cohort.

In a clinical setting, deviations of red blood cell count are often only recognized when values are not within the normal range. Most studies addressing the importance of $\mathrm{Hb}$ and/or $\mathrm{Hc}$ in COPD have focused on the common definitions of anemia and polycythemia, ${ }^{32-34}$ despite the fact that the respective cutoff values have never been validated with regard to their prognostic value in COPD. To evaluate the clinical impact of $\mathrm{Hb}$ levels in detail and to answer the question whether there is an optimal threshold and where it is, we checked all percentiles of $\mathrm{Hb}$ and found optimal cutoff values of $14.3 \mathrm{~g} / \mathrm{dL}$ for females and $15.1 \mathrm{~g} / \mathrm{dL}$ for males for predicting long-term survival. These cutoff values ultimately chosen optimized the prediction, although the nature of the statistical analysis, in combination with the still finite number of subjects, resulted in broad and overlapping formal confidence intervals. The fact that these values are markedly higher than the common definitions of non-anemia (females $\geq 12 \mathrm{~g} / \mathrm{dL}$, males $\geq 13 \mathrm{~g} / \mathrm{dL}$ ) suggests that, in COPD, Hb levels are related to prognosis at levels far away from common "anemia." Noteworthy enough, when the optimal cutoff values were introduced as categorical variables in the multivariate model, $\mathrm{Hb}$ remained a significant independent predictor, despite the fact that categories might be associated with a loss of statistical power, compared to continuous variables. The discrepancy points toward a nonlinear relationship of $\mathrm{Hb}$ to survival. In view of this, it is even more remarkable that this nonlinear transition occurred far above the established World Health Organization cutoff values. Of course, this does not invalidate the usefulness of those values, which are for clinical purposes, and not for prediction of survival. Our data point out that cutoff values must be adapted to their purpose and that patients with $\mathrm{Hb}$ values above anemia levels can also be at risk. Possibly, a higher $\mathrm{Hb}$ level in the presence of chronic hypoxemia prior to treatment reflects adequate bone marrow function ${ }^{35}$ and response to inflammation and/or hypoxia ${ }^{26,31}$ and therefore indicates patients with a better prognosis.

Of course, our findings are purely observational. Thus, the thresholds proposed should be validated prospectively in separate cohorts. In particular, the study design does not allow establishing a novel threshold for red blood cell transfusion. The association between higher threshold values and better prognosis most likely reflects an adequate physiological response to chronic respiratory failure in these patients. Which mechanisms are underlying these associations, possibly defining a specific phenotype of COPD, has to be addressed in future studies.

One of the limitations of the present study is that it was not designed to identify the patterns of pathophysiological factors underlying the abnormalities of $\mathrm{Hb}$. We tried to deal with this as far as possible by the exclusion of known, trivial causes of anemia, in order to keep the analysis as unbiased as possible. With regard to the prognostic impact of $\mathrm{Hb}$, we also accounted for additional comorbidities and typical concomitant medication, which, however, cannot be fully distracted from COPD. In addition, data were collected over a long period of time, and a change in therapeutic attitude, including prescribed medication, cannot be ruled out. Although the subjects were seen regularly at follow-up visits in the hospital, adherence to LTOT and NIV could not be assessed over the total study period. 


\section{Hemoglobin Levels Above Anemia Thresholds}

Finally, blood gas values were obtained from the earlobe and were not available without oxygen supply in all subjects, which could affect their value as potential predictors.

\section{Conclusions}

In conclusion, in subjects with severe COPD and chronic respiratory failure requiring NIV and LTOT, Hb levels were gradually linked to long-term survival, and a higher $\mathrm{Hb}$ was associated with better survival. This is in line with known data. However, as optimal independent predictors of survival, we identified $14.3 \mathrm{~g} / \mathrm{dL}$ for females and $15.1 \mathrm{~g} / \mathrm{dL}$ for males, which corresponded to the 58th percentiles of the distributions. These values are markedly higher than the World Health Organization's definition of anemia or similar clinical criteria that are suited to define a definite pathological condition but do not fully exploit the prognostic potential of $\mathrm{Hb}$ values in severe COPD.

\section{REFERENCES}

1. Rabe KF, Beghé B, Luppi F, Fabbri LM. Update in chronic obstructive pulmonary disease 2006. Am J Respir Crit Care Med 2007; 175(12):1222-1232.

2. Barnes PJ, Celli BR. Systemic manifestations and comorbidities of COPD. Eur Respir J 2009;33(5):1165-1185.

3. Fabbri LM, Rabe KF. From COPD to chronic systemic inflammatory syndrome? Lancet 2007;370(9589):797-799.

4. Incalzi RA, Corsonello A, Pedone C, Battaglia S, Paglino G, Bellia $\mathrm{V}$; Extrapulmonary Consequences of COPD in the Elderly Study Investiators. Chronic renal failure: a neglected comorbidity of COPD. Chest 2010;137(4):831-837.

5. Kollert F, Müller C, Tippelt A, Jörres RA, Heidinger D, Probst C, et al. Anaemia in chronic respiratory failure. Int J Clin Pract 2011; 65(4):479-486.

6. Similowski T, Agustí A, MacNee W, Schönhofer B. The potential impact of anaemia of chronic disease in COPD. Eur Respir J 2006; 27(2):390-396.

7. Chambellan A, Chailleux E, Similowski T; ANTADIR Observatory Group. Prognostic value of the hematocrit in patients with severe COPD receiving long-term oxygen therapy. Chest 2005;128(3):12011208. Erratum in: Chest 2006;129(3):831.

8. Cote C, Zilberberg MD, Mody SH, Dordelly LJ, Celli B. Haemoglobin level and its clinical impact in a cohort of patients with COPD. Eur Respir J 2007;29(5):923-929.

9. Rasmussen L, Christensen S, Lenler-Petersen P, Johnsen SP. Anemia and 90-day mortality in COPD patients requiring invasive mechanical ventilation. Clin Epidemiol 2010;3:1-5.

10. Wade JP, Pearson TC, Russell RW, Wetherley-Mein G. Cerebral blood flow and blood viscosity in patients with polycythaemia secondary to hypoxic lung disease. BMJ (Clin Res Ed) 1981;283(6293): 689-692.

11. Wedzicha JA, Rudd RM, Apps MC, Cotter FE, Newland AC, Empey DW. Erythrapheresis in patients with polycythaemia secondary to hypoxic lung disease. BMJ (Clin Res Ed) 1983;286(6364):511514.

12. Weisse $\mathrm{AB}$, Moschos $\mathrm{CB}$, Frank MJ, Levinson GE, Cannilla JE,
Regan TJ. Hemodynamic effects of staged hematocrit reduction in patients with stable cor pulmonale and severely elevated hematocrit levels. Am J Med 1975;58(1):92-98.

13. Menon D, York EL, Bornstein RA, Jones RL, Sproule BJ. Optimal hematocrit and blood viscosity in secondary polycythemia as determined from cerebral blood flow. Clin Invest Med 1981;4(2):117121

14. Klinger JR, Hill NS. Right ventricular dysfunction in chronic obstructive pulmonary disease. Evaluation and management. Chest 1991;99(3):715-723.

15. Harrison BD, Stokes TC. Secondary polycythaemia: its causes, effects and treatment. Br J Dis Chest 1982;76(4):313-340.

16. Segel N, Bishop JM. The circulation in patients with chronic bronchitis and emphysema at rest and during exercise, with special reference to the influence of changes in blood viscosity and blood volume on the pulmonary circulation. J Clin Invest 1966;45(10): 1555-1568.

17. Criner GJ. Effects of long-term oxygen therapy on mortality and morbidity. Respir Care 2000;45(1):105-118.

18. McMullin MF, Bareford D, Campbell P, Green AR, Harrison C, Hunt B, et al. Guidelines for the diagnosis, investigation and management of polycythaemia/erythrocytosis. Br J Haematol 2005; 130(2):174-195.

19. Clinical indications for noninvasive positive pressure ventilation in chronic respiratory failure due to restrictive lung disease, COPD, and nocturnal hypoventilation: a consensus conference report. Chest 1999; 116(2):521-534.

20. Nutritional anaemias. Report of a WHO scientific group. World Health Organ Tech Rep Ser 1968;405:5-37.

21. Stevens LA, Coresh J, Greene T, Levey AS. Assessing kidney function: measured and estimated glomerular filtration rate. N Engl J Med 2006;354(23):2473-2483.

22. Miller MR, Hankinson J, Brusasco V, Burgos F, Casaburi R, Coates A, et al; ATS/ERS Task Force. Standardisation of spirometry. Eur Respir J 2005;26(2):319-338.

23. Quanjer PH, Tammeling GJ, Cotes JE, Pedersen OF, Peslin R, Yernault JC. Lung volumes and forced ventilatory flows. Report Working Party Standardization of Lung Function Tests, European Community for Steel and Coal. Official Statement of the European Respiratory Society. Eur Respir J 1993;(Suppl 16):5-40.

24. American Thoracic Society Committee on Proficiency Standards for Clinical Pulmonary Function Laboratories. ATS statement: guidelines for the six-minute walk test. Am J Respir Crit Care Med 2002; 166(1):111-117.

25. Enright PL, Sherrill DL. Reference equations for the six-minute walk in healthy adults. Am J Respir Crit Care Med 1998;158(5 Pt 1): 1384-1387.

26. Macnee W. Right heart function in COPD. Semin Respir Crit Care Med 2010;31(3):295-312.

27. Kent BD, Mitchell PD, McNicholas WT. Hypoxemia in patients with COPD: cause, effects, and disease progression. Int J Chron Obstruct Pulmon Dis 2011;6:199-208.

28. Quintó L, Aponte JJ, Menéndez C, Sacarlal J, Aide P, Espasa M, et al. Relationship between haemoglobin and haematocrit in the definition of anaemia. Trop Med Int Health 2006;11(8):1295-302.

29. Budweiser S, Jörres RA, Riedl T, Heinemann F, Hitzl AP, Windisch $\mathrm{W}$, et al. Predictors of survival in COPD patients with chronic hypercapnic respiratory failure receiving noninvasive home ventilation. Chest 2007;131(6):1650-1658.

30. Windisch W, Haenel M, Storre JH, Dreher M. High-intensity noninvasive positive pressure ventilation for stable hypercapnic COPD. Int J Med Sci 2009;6(2):72-76. 


\section{Hemoglobin Levels Above Anemia Thresholds}

31. Kolodziej MA, Jensen L, Rowe B, Sin D. Systematic review of noninvasive positive pressure ventilation in severe stable COPD. Eur Respir J 2007;30(2):293-306.

32. John M, Hoernig S, Doehner W, Okonko DD, Witt C, Anker SD. Anemia and inflammation in COPD. Chest 2005;127:825-829.

33. John M, Lange A, Hoernig S, Witt C, Anker SD. Prevalence of anemia in chronic obstructive pulmonary disease: comparison to other chronic diseases. Int J Cardiol 2006;111(3):365-370.
34. Krishnan G, Grant BJ, Muti PC, Mishra A, Ochs-Balcom HM, Freudenheim JL, et al. Association between anemia and quality of life in a population sample of individuals with chronic obstructive pulmonary disease. BMC Pulm Med 2006;6:23.

35. Weil JV, Jamieson G, Brown DW, Grover RF. The red cell massarterial oxygen relationship in normal man. Application to patients with chronic obstructive airway disease. J Clin Invest 1968;47(7): $1627-1639$. 